\title{
A longitudinal study of incidence and pregnancy outcome of abruption placenta at the-tertiary hospital in Gambia
}

\begin{abstract}
Background: Placenta abruption is the leading cause of vaginal bleeding in the latter half of pregnancy and obstetrics haemorrhage the most common cause of maternal death in sub-Saharan Africa. The aim of the study was to determine incidence, risk factors and management outcomes of abruption in our setting.

Methods: data on pregnancy, delivery, maternal and perinatal outcomes were collected using a structured data collection tool from January to December 2014 at Edward Francis Small Teaching Hospital. Descriptive statistics was generated and analysed using Stata statistical software. A binary variable regression analysis with confidence interval set at $95 \%$ and Odd ratio was used for test of significance.

Results: there were 4640 maternities and 111 had abruption at the rate of 24/1000 maternities $(2.4 \%)$. Increasing maternal age $>31$ years and parity $>4$ were associated with high frequency of abruption $36.3 \%$ and $54.1 \%$ respectively. The commonest risk factor was hypertensive disorder in pregnancy $(59.5 \%)$. The stillbirth rate was $53 \%$, predominantly fresh stillbirth $(46.8 \%)$. However, maternal age $<=20$ years, preeclampsia/eclampsia and chronic hypertensive disorders in pregnancy had some association with adverse perinatal outcome; OR 1.71 (CI-0.43, 6.81); 2.09 (CI-0.84, $5.21) ; 1.64$ (CI-0.51, 5.24) respectively. There was no maternal death among the cohort.

Conclusion: incidence of abruption placenta was high $(2.4 \%)$ with significant adverse neonatal outcome. Hypertensive disorder in pregnancy was the commonest risk factor of abruption placenta in the Gambia.
\end{abstract}

Keywords: abruption, incidence, management, outcome
Volume 5 Issue 2 - 2019

\author{
Matthew Anyanwu, ${ }^{1,2}$ Claudette Amuzu, \\ Mustapha bittaye, ${ }^{1,2}$ Patrick Idoko ${ }^{1,2}$ \\ 'Edward Francis Small Teaching Hospital, Banjul, Gambia \\ ${ }^{2}$ School of Medical and Allied Health Sciences, University of the \\ Gambia, Gambia
}

Correspondence: Matthew Anyanwu, Senior Lecturer, University of the Gambia School of Medicine and Allied Sciences department of Obstetrics and Gynaecology, P.O.Box 1646 UTG Banjul, Gambia, Tel (220)-9922933;(220)-7786700),

Email anyanwum@yahoo.com

Received: February 02, 2019 | Published: March 19, 2019

\section{Introduction}

Placenta abruption is the leading cause of vaginal bleeding in the latter half of pregnancy. ${ }^{1}$ It is associated with significant maternal and fetal morbidity and, ultimately, maternal and fetal death. Abruption is often an unanticipated emergency; a small bleed can suddenly evolve into a major abruption. It was described by Hall \& Wagaarachchi ${ }^{2}$ as an important cause of fetal demise even in the first half of pregnancy. Therefore, using age of viability to define abruption may underestimate the incidence as age of fetal viability varied so widely in different populations. The incidence reported in various studies varies in different populations and different study designs. Ananth et al., ${ }^{3}$ documented that the USA-based studies found a higher incidence in cohort $(0.81 \%)$ and case-control studies $(0.37 \%)$ than the non-USA studies $(0.60 \%$ and $0.26 \%$, respectively). In Finland a large dataset on demographic characteristics, pregnancy and delivery of over 1.5 million maternities showed an abruption incidence of 395/ 100000 $(0.4 \%)^{4}$ which was a $31 \%$ decrease from 1980 to 2005 . However, the incidence in South Eastern Nigeria increased from $0.4 \%$ in $1989^{5}$ to $0.8 \%$ in $2013 .{ }^{6}$ There is no published data on the incidence of abruption in the Gambia.

Abruptions are usually associated with pain and, in contrast with labour pain, the pain can be constant; however, labour may be concurrent. The pain is likely to be secondary to the infiltration of blood into the myometrium (Couvelaire uterus). ${ }^{7}$ A Couvelaire uteri, named after Alexandre Couvelaire, may extend as large pressure is generated in the uterus during contractions. The uterus appears severely bruised by the infiltrated blood, becomes weak and may contract poorly, contributing to postpartum haemorrhage. In extreme cases the uterus can rupture. ${ }^{7}$ Therefore, prompt diagnosis is essential in the effective management of placental abruption.

Placental abruption is a clinical diagnosis. Ultrasound is useful to confirm fetal viability/death and exclude a placenta praevia. Tikkanen et al., ${ }^{8}$ found that vaginal bleeding (70\%), abdominal pain (51\%), bloody amniotic fluid (50\%), and fetal heart rate abnormalities (69\%) were the most common manifestations. Neither bleeding nor pain was present in $19 \%$ of cases. Therefore, abruption could be concealed or revealed and a mixed type- the combination of both is a possibility.

The maternal effect of abruption depends primarily on its severity, whereas its effect on the fetus is determined both by its severity and the gestational age at which it occurs. ${ }^{9}$ It is an important cause of perinatal mortality and morbidity. Abruption involving more than $50 \%$ of the placenta is frequently associated with fetal death. ${ }^{9}$ Recognized associated risk factors as true aetiology has not been elucidated include: prior abruption, smoking, trauma, cocaine use, multifetal gestation, hypertension, preeclampsia, thrombophilias, advanced maternal age, preterm pre-labour rupture of the membranes, intrauterine infections, and hydramnios. ${ }^{1,7,9,10}$ Recent studies suggest association of social disparity, ${ }^{11}$ male sex, ${ }^{12}$ and suboptimal maternal 
weight gain in pregnancy ${ }^{13}$ and major congenital anomalies ${ }^{14}$ with abruption placenta. These are new frontiers of risk factors whereas, previous suggestion of folic acid deficiency as a risk factor is unfounded. ${ }^{15}$

Placenta abruption is the leading cause of vaginal bleeding in the latter half of pregnancy and obstetrics haemorrhage the most common cause of maternal death in the Gambia. ${ }^{16,17}$ The knowledge of risk factors may have significant impact on the management options and outcome of abruption placenta. Therefore, the objective of this study was to determine incidence, risk factors and maternal and neonatal outcomes of abruption Placentae (AP) at Edward Francis Small Teaching Hospital-the only teaching hospital in the Gambia and a major referral centre serving 1.9 million people.

\section{Methodology}

The study design was a longitudinal descriptive study of abruption placenta at EFSTH from January to December 2014. The study subjects were all cases of abruption that occurred within the period under review. Diagnosis of abruption placenta was based on the clinical findings of vaginal bleeding after the age of viability, abdominal pain, tense hard abdomen and or retroplacental clot after delivery. A data collection tool was created to extract information on pregnancy, delivery, maternal and perinatal outcomes of the cases of abruption placenta. Data source was the patient's case notes, labour ward register, the postnatal and neonatal ward registers and the annual maternity unit dataset. There was no sample size calculation as data collection was retrospective and period under review was one year which was meant to estimate incidence of abruption in a major referral tertiary hospital in the Gambia. The denominator of the estimation of incidence was based on total number of maternities from January to December 2014 which was extracted from annual maternity unit dataset.

There were no exclusion criteria. The inclusion criteria were all cases of abruption after 28 weeks of gestation. Main outcome measures include demographic characteristics of the study population, incidence, and maternal comorbidity, perinatal and early neonatal conditions. Descriptive statistics was generated using Stata statistical software. A binary variable regression analysis was performed with confidence intervals and odd ratios to test significance of the associations.

\section{Results}

There were 4640 maternities from January to December 2014 out of which 111 were complicated by abruption placenta. The incidence of abruption placenta was 24 in 1000 maternities (2.4\%) during the period under review.

(Table 1). Sociodemographic characteristics of the study population showed that increasing maternal age ( $>31$ years) and parity $(>4)$ were associated with high frequency of abruption $36.3 \%$ and $54.1 \%$ respectively. The Mandika (19.8\%), Wollof (18.0\%) and Fula (18.9\%) tribes had comparable rates of abruption and majority $(68.5 \%)$ were urban dwellers. Table 2, Logistic regression with neonatal outcome as a binary variable and outcome of interest suggested some associations from the odd ratios, that Preeclampsia/eclampsia and non-proteinuric hypertension had some association with adverse neonatal outcome (OR; 2.09 and 1.64 respectively). Age disaggregation also showed some association ( $<20$ and $>25$ years; OR; 1.71 and 1.59 respectively) stronger with extreme young age. Figure 1 Referrals; majority (91\%) of the abruption were referred from other health facility. Figure 2 Neonatal outcome; there were more stillbirths (FSB 46.8\%; MSB $6.3 \%$ ) than live births $(41.4 \%)$. Early neonatal death was $5.4 \%$. Monthly distribution of abruption placenta; suggested that the peak period of abruption in the Gambia was September which was the peak period of rainy season and maternity services at EFSTH.

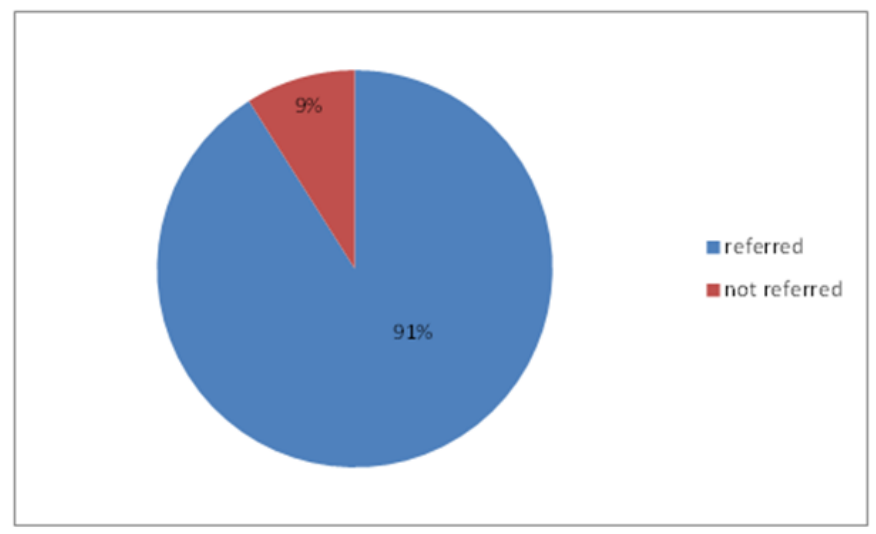

Figure I Referrals.

Table I Sociodemographic characteristics of the study population

\begin{tabular}{lll}
\hline Age (Years) & $(\mathrm{n}=\mathrm{III})$ & $\mathbf{( \% )}$ \\
\hline$<=20$ & 14 & 12.6 \\
$2 \mathrm{I}-25$ & 26 & 23.4 \\
$26-30$ & $3 \mathrm{I}$ & 27.9 \\
$3 \mathrm{I}+$ & 40 & 36.3 \\
Parity & & \\
$0-\mathrm{I}$ & 19 & 17.1 \\
0I-Mar & 24 & 21.6 \\
$>4$ & 60 & 54.1 \\
na & 8 & 7.2 \\
& $(\mathrm{n}=\mathrm{III})$ & $(\%)$
\end{tabular}

Tribe

$\begin{array}{lll}\text { MANDINKA } & 22 & 19.8 \\ \text { WOLOF } & 20 & 18 \\ \text { FULA } & 21 & 18.9 \\ \text { JOLA } & 6 & 5.4 \\ \text { OTHERS } & 10 & 9 \\ \text { Na } & 32 & 28.8 \\ \text { Address } & & \\ \text { Rural } & 35 & 31.5 \\ \text { Urban } & 76 & 68.5\end{array}$


Table 2 Logistic regression with neonatal outcome as a binary variable and outcome of interest

\begin{tabular}{|c|c|c|c|c|c|}
\hline Factor & Level & Alive & Dead & & \\
\hline $\mathrm{N}$ & & 46 & 65 & OR $(95 \% \mathrm{Cl})$ & $\mathrm{P}$-value \\
\hline \multirow[t]{3}{*}{ Maternal_comorbidity } & None & $25(56 \%)$ & $26(42 \%)$ & Ref & \\
\hline & Pre-eclampsia /eclampsia/ PET & $13(29 \%)$ & $26(42 \%)$ & $2.09(0.84,5.21)$ & 0.112 \\
\hline & Hypertension & $7(16 \%)$ & $10(16 \%)$ & I.64 (0.5I, 5.24) & 0.402 \\
\hline \multirow[t]{2}{*}{ Admission_Hb } & $<|0 g / d|$ & $30(67 \%)$ & 47 (75\%) & Ref & \\
\hline & $>=|0 g / d|$ & 15 (33\%) & $16(25 \%)$ & $0.63(0.26,1.53)$ & 0.305 \\
\hline \multirow[t]{4}{*}{ Age group } & $<=20$ & $4(9 \%)$ & $10(15 \%)$ & I.7I $(0.43,6.8 I)$ & 0.444 \\
\hline & $21-25$ & $14(30 \%)$ & $12(18 \%)$ & $0.65(0.23,1.86)$ & 0.422 \\
\hline & $26-30$ & II (24\%) & $20(31 \%)$ & I.59 $(0.57,4.50)$ & 0.377 \\
\hline & $31+$ & 17 (37\%) & $23(35 \%)$ & & \\
\hline
\end{tabular}

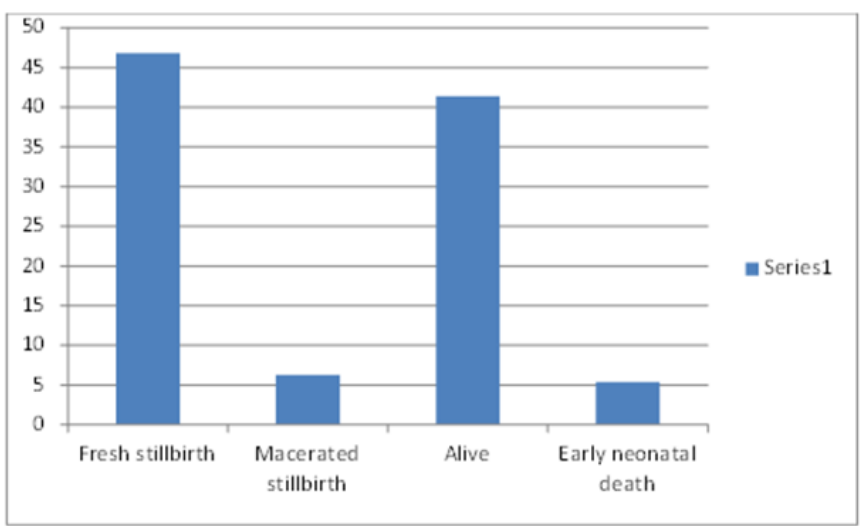

Figure 2 Neonatal outcome.

\section{Discussion}

The incidence of abruption was estimated at 24/1000 maternities (2.4\%) which was high compared to studies performed elsewhere. The Scandinavian study by Tikkanen et al., ${ }^{4}$ showed $31 \%$ decreasing trend from the 1980 s to 2005 . However, some other studies in similar geo-cultural and socioeconomic settings with our study population,, 6 showed increasing trend of abruption placenta. Although, there is more to high incident rate we had in the study. The hospital is the major referral centre in the country and antepartum haemorrhage at any peripheral health facility is referred. The blood bank is also centralized in our hospital. Therefore, most referrals from other hospitals due to bleeding are referred to Edward Francis Small Teaching hospital as revealed in Figure 1 that $91 \%$ of the patients who had abruption were referred.

Increasing maternal age ( $>31$ years) and parity $(>4)$ were associated with high frequency of abruption, $36.3 \%$ and $54.1 \%$ respectively. Maternal age was strongly associated with abruption, with very young and especially older women at substantially increased risk. A study from Japan found the distribution of placental abruption in women older than 35 years was greater than those who were younger..$^{18}$ This was similar to studies conducted elsewhere. ${ }^{3-5}$ Our study had similar discrimination as increased maternal age was associated more with abruption than young age. However, adverse neonatal outcome had increased odd to be associated with younger age (Table 2).
Some scholars working elsewhere have suggested in their study that abruption placenta is more associated with chronic hypertension than pre-eclampsia (odds ratio of 1.81 (95\% CI: 1.62-2.02) Ananth et al. ${ }^{3}$ In our study we discovered that preeclampsia was associated with abruption than chronic or non-proteinuric hypertensive disorder in pregnancy. This discovery is yet emphasizing the multi systemic and multi dysfunctional protégés of preeclampsia/eclampsia. Similarly, the association of adverse perinatal outcome was more with preeclampsia/eclampsia than non-proteinuric hypertension (OR; 2.09 vs1.64 respectively) (Table 2).

The study by Ananth et al., ${ }^{3} \&$ Ozummba et al., ${ }^{5}$ showed consistent association of high blood pressure and abruption. There are many other known risk factors of abruption placenta ${ }^{1,9-14}$ but folic acid deficiency is no longer supported by available evidence. ${ }^{15,19}$ Recurrence risk of abruption is well established ${ }^{20,21}$ but was not factored in our study. Our study focused more on maternal comorbidity and neonatal outcome. Regarding management outcomes, some other study elsewhere suggests a correlation with pregnancy induced hypertension (PIH), disseminated intravascular coagulopathy (DIC), blood transfusion and Couvelaire uterus and poor perinatal outcomes. ${ }^{22}$ In our study we observed a correlation of maternal age and maternal coexisting morbidity to neonatal outcome. A binary variable regression analysis was performed which suggests OR (ratios) of likely adverse neonatal outcome in abruption with preeclampsia/eclampsia (2.09), chronic hypertension (1.64) and young maternal age (1.79). With the available evidence it is imperative therefore, that placental abruption with these clinical characteristics should be closely monitored and prompt delivery should occur preferably at tertiary care centres with adequate materno-neonatal intensive care facilities.

Interestingly, we observed that maternal haemoglobin concentration at admission in the hospital had no correlation with adverse neonatal outcome. The acute blood loss of abruption placenta is of maternal in origin therefore priority in the initial management should always be maternal. The stillbirth rate and early neonatal mortality was $53 \%$ and $5.4 \%$ respectively. This certainly agreed with established fact that abruption is associated with adverse perinatal and neonatal outcome. ${ }^{20,21}$ There was no maternal death among the cohort that had abruption. The aggressive management with clear intention to save the mother irrespective of neonatal outcome may have been the reason for this result although not evaluated in this study. 
The seasonal nature of abruption in our practice was not clear; however the peak period in our study was September (Figure 2) which correlates with peak of raining and malaria season in the Gambia. In sub-Saharan Africa, the rates of both pre-eclampsia and malaria increase during the rainy season. ${ }^{23-26}$ Several studies in the region have suggested an association between malaria and pre-eclampsia. ${ }^{27-30}$ In this study, an association between pre-eclampsia and placental abruption was established which may explain the peak incidence of placental abruption at the peak of the malaria season (September). However, more research may be required to underscore seasonal probability and possible need for adequate health service planning. The study being retrospective had some inherent shortfall as in data collection and certain variables not found in the case notes. The new frontiers of risk factor of abruption would be interesting to know how our setting respond to it which invariably a research interest in the future.

\section{Conclusion}

Incidence of abruption placenta was high $(2.4 \%)$ with significant adverse neonatal outcome. Hypertensive disorder in pregnancy was the most common risk factor of abruption in the Gambia.

\section{Recommendation}

Abruption placenta is a common obstetrics emergency with high incidence at EFSTH - a major referral centre. The study suggests that the condition is associated with high perinatal mortality. Placental abruption was associated with pre-eclampsia and adverse perinatal outcomes were more associated with pre-eclampsia / eclampsia. Therefore, we recommend that pregnancies complicated with hypertensive disorders should receive immediate attention by the specialist at the tertiary hospital. Similarly, pregnancies at the extremes of maternal age should be supervised by specialist obstetricians as these may lead to early recognition of complications and promote prompt treatment. The seasonal potential of abruption needs further research, however, proactive health system service delivery planning may consider adequate supplies and effective blood bank services during peak raining and malaria seasons in the Gambia.

\section{Acknowledgments}

The authors wish to thank maternity record staff for their support in the data collection of this study.

\section{Ethics approval and consent to participate}

The authors wrote to the Ethics Committee of the Edward Francis Small Teaching Hospital (EFSTH) informing them of the study and justifying a need for the study. The EFSTH Ethics Committee approved the study. Consent to participate in the study was not applicable as this was a retrospective analysis of medical records and maternity dataset.

\section{Authors' contributions}

MA, PI and MB conceived the study and contributed to the study design, data collection and data analysis. MA wrote the first manuscript. CA contributed in the design and data collection of the study. All authors read and approved the final manuscript.

\section{Conflicts of interest}

The authors declare that they have no competing interests.

\section{Availability of data and materials}

The datasets generated and/or analyzed during this study are available from the corresponding author on reasonable request.

\section{References}

1. Royal College of Obstetricians and Gynaecologists. Antepartum Haemorrhage. Green-top Guideline 63. London: RCOG. 2011.

2. Hall MH, Wagaarachchi P. Antepartum haemorrhage. In: Maclean AB, Neilson JP, editors. Maternal Morbidity and Mortality. London: RCOG Press; 2002. p. 227-240.

3. Ananth CV, Savitz DA, Williams MA. Placental abruption and its association with hypertension and premature rupture of membranes: a methodologic review and meta-analysis. Obstet Gynecol. 1996;88:309318 .

4. Tikkanen M, Riihimäki O, Gissler M, et al. Decreasing incidence of placental abruption in Finland during 1980-2005. Acta Obstet Gynecol Scand. 2012;91(9):1046-1052.

5. Ozumba BC. Abruptio placentae at the University of Nigeria Teaching Hospital, Enugu: a 3-year study. Aust $N Z$ J Obstet Gynaecol. 1989;29(2):117-120

6. Igwegbe AO, Eleje GU, Okpala BC. Management outcomes of abruptio placentae at Nnamdi Azikiwe University Teaching Hospital, Nnewi, Nigeria. Niger J Med. 2013;22(3):234-238.

7. Obstetrical haemorrhage. In: Cunningham FG, Macdonald PC, Gant NF, et al editors. Williams Obstetrics 20th ed. Appleton \& Lange; 1996.

8. Tikkanen M, Nuutila M, Hiilesmaa V, et al. Clinical presentation and risk factors of placental abruption. Acta Obstet Gynecol Scand. 2006;85:700705 .

9. Oyelese Y, Ananth CV. Placental abruption. Obstet Gynecol. 2006;108(4):1005-1016.

10. Ananth CV, Oyelese Y, Srinivas N, et al. Preterm premature rupture of membranes, intrauterine infection, and oligohydramnios: risk factors for placental abruption. Obstet Gynecol. 2004;104:71-7.

11. Räisänen S, Gissler M, Nielsen HS, et al. Social disparity affects the incidence of placental abruption among multiparous but not nulliparous women: a register-based analysis of 1,162,126 singleton births. Eur $J$ Obstet Gynecol Reprod Biol. 2013;171(2):246-251.

12. Tikkanen M, Metsäranta M, Gissler M, et al. Male fetal sex is associated with earlier onset of placental abruption. Acta Obstet Gynecol Scand. 2010;89(7):916-923.

13. Salihu HM, Diamond E, August EM, et al. Maternal pregnancy weight gain and the risk of placental abruption. Nutr Rev. 2013;71(Suppl ):S9 17.

14. Riihimäki $\mathrm{O}$, Metsäranta $\mathrm{M}$, Ritvanen $\mathrm{A}$, et al. Increased prevalence of major congenital anomalies in births with placental abruption. Obstet Gynecol. 2013;122(2 Pt 1):268-274.

15. Ray JG, Laskin CA. Folic acid and homocysteine metabolic defects and the risk of placental abruption, pre-eclampsia and spontaneous pregnancy loss: A systematic review. Placenta. 1999;20:519-529.

16. Hoestermann CF, Ogbaselassie G, Wacker J, et al. Maternal mortality in the main referral hospital in The Gambia, west Africa. Trop Med Int Health. 1996;1(5):710-717.

17. Idoko P, Anyanwu M, Bass S. A retrospective analysis of trends in maternal mortality in a Gambian tertiary health centre. BMC Res Notes. 2017;10:493.

18. Seyedhosseini H. Risk factors for placental abruption. J Res Med Sci. 2013;18:422-426.

19. Nurk E, Tell GS, Refusm H, et al. Associations between maternal methenetetrahydrofolate reductase polymorphisms and adverse outcomes of pregnancy: The Hordaland Homocysteine Study. Am J Med. $2004 ; 117: 26-31$

20. Tikkanen M. Etiology, clinical manifestations, and prediction of placental abruption. Acta Obstet Gynecol Scand. 2010;89:732-40. 
21. Pitaphrom A, Sukcharoen N. Pregnancy outcomes in placental abruption. J Med Assoc Thai. 2006;89(10):1572-1578.

22. Bergstrom S, Povey G, Songane F, et al. Seasonal incidence of eclampsia and its relationship to meteorological data in Mozambique. $J$ Perinat Med. 1992;20:153-158.

23. Crowther CA. Eclampsia at Harare Maternity Hospital. An epidemiological study. S Afr Med J. 1985;68:927-929.

24. Sartelet H, Rogier C, Milko-Sartelet I, et al. Malaria associated preeclampsia in Senegal. Lancet. 1996;347:1121.

25. Wacker J, Schulz M, Fruhauf J, et al. easonal change in the incidence of preeclampsia in Zimbabwe. Acta Obstet Gynecol Scand. 1998;77:712716
26. Muehlenbachs A, Mutabingwa TK, Edmonds S, et al. Hypertension and maternal-fetal conflict during placental malaria. PloS Medicine. 2006;49: 179-191.

27. Sartelet H, Rogier C, Milko-Sartelet I, et al. Malaria-associated preeclampsia in Senegal. Lancet. 1996;347:1121.

28. Ndao CT, Dumont A, Flevet N, et al. Placental Malarial Infection as a Risk Factor for Hypertensive Disorders During Pregnancyin Africa: A case control study in an Urban Area of Senegal, West Africa. Am J Epidemiol. 2009;170(7):847-853.

29. Adam I, Elhassan ME, Mohmmed AA, et al. Malaria and pre-eclampsia in an area with unstable malaria transmission in Central Sudan. Malar J. $2011 ; 10: 258$ 